\title{
Microbial Contamination of Donated Umbilical Cord Blood
}

\author{
Jeong Su Park ${ }^{1,2,4}$, Sue Shin ${ }^{1,2,4}$, Jong Hyun Yoon ${ }^{1,2,4}$, Eun Youn Roh ${ }^{1,2,4}$, Ju Young Chang ${ }^{3}$, Eui-Chong Kim ${ }^{1}$ \\ ${ }^{1}$ Department of Laboratory Medicine, Seoul National University College of Medicine, ${ }^{2}$ Department of \\ Laboratory Medicine, Seoul National University Boramae Hospital, ${ }^{3}$ Department of Pediatrics, Seoul National \\ University Boramae Hospital, ${ }^{4}$ Seoul Metropolitan Government Public Cord Blood Bank, Seoul, Korea
}

\begin{abstract}
Background: Testing for possible microorganism contamination in umbilical cord blood (UCB) is essential for validating the product safety of allogeneic cellular therapeutics. We analyzed the level of contamination and related factors at the largest public cord blood bank in Korea. In addition, we also studied the influence of cryopreservation on contaminating microorganisms.

Methods: UCB was collected, transported, processed, and stored according to standard operating procedures. Microbial detection and identification was performed using a conventional automated blood culture system (BacT/ALERT; bioMérieux, France) with an inoculum of 5-10 $\mathrm{mL}$ plasma for pre-freezing UCB. Forty randomly selected non-conforming units were thawed and studied for microbiologic recovery with an inoculum of $2.5 \mathrm{~mL}$.
\end{abstract}

Results: Among a total of 21,236 UCB, 677 (3.19\%) were positive for culture. The most frequently identified organism was Lactobacillus spp. (17.2\%), followed by Bacteroides spp. (10.1\%), coagulase negative staphylococcus $(6.4 \%)$, except the unidentified grampositive bacillus $(21.4 \%)$. The contamination rate was higher in vaginal delivery specimens than in cesarean section specimens $(4.1 \%$ vs. $0.7 \%, P<0.001)$, and differed by collection center $(0.7-25.4 \%, P<0.001)$. Only $55 \%$ after-thaw cultures of non-conforming units were positive.

Conclusion: We determined the contamination rate of UCB in Korea in a large sample size. The results of this study could be used as baseline data at collection centers for quality control purposes. The low recovery rate of microorganisms after cryopreservation presents a possible way to rescue some non-conforming cord blood units, although further study is needed to confirm the reduction of microbiological burden. (Ann Clin Microbiol 2013;16:39-44)

Key Words: Bacteria, Biological specimen banks, Quality control, Umbilical cord blood

\section{서 론}

현재 제대혈은 조혈모세포 등 줄기세포의 주요한 공급원이 되고 있다. 채취된 제대혈에서 유핵세포만이 농축 처리되어 제대 혈제제로 냉동보관되는데 이들 제대혈제제의 이용이 증가하면 서 그 처리와 보관에 관한 정도관리 및 규제도 강화되는 추세 이다. 국외에서는 대표적으로 Foundation for the Accreditation of Cellular Therapy (FACT), American Association of Blood Banks (AABB), Food and Drug Administration 등에서 발표한 지침이 있으며[1-3], 국내에서는 2005년에 보건복지부 표준업 무지침이 발표되었고, 2011년에는 제대혈 관리 및 연구에 관한 법률이 포괄적으로 시행되기 시작하였다[4]. 이런 규제의 목적은 제대혈제제의 품질과 안전성을 확보하는 것이라 할 수 있다. 제대혈제제의 안전성은 채취된 제대혈의 혈액전파성감염 표

Received 14 August, 2012, Revised 5 November, 2012

Accepted 5 November, 2012

Correspondences: Jong Hyun Yoon and Sue Shin, Department of Laboratory Medicine, Seoul National University Boramae Hospital, 20 Boramae-ro 5-gil, Dongjak-gu, Seoul 156-707, Korea. (Tel) 82-2-870-2601, (Fax) 82-2-870-2620, (E-mail) slice@paran.com
지자 음성 및 혈액배양 음성으로 확인할 수 있다. 일반적으로 제대혈의 처리과정은 관리구역에서 이루어지도록 되어 있으므 로[4], 제대혈은 처리과정보다는 채취 혹은 배양 시의 기술적 오류에 의해 세균에 오염될 가능성이 있다. 즉, 분만 과정 중에 비뇨생식기나 장내 정상균무리에 오염되었거나 정상균무리나 환경균에 오염된 제대에서, 채취 전 소독을 통한 오염제거가 덜 되었을 가능성이 크다. 또한 혈액배양병에 옮겨 담는 과정 중에 미생물에 오염되는 경우도 있을 수 있다. 보건복지부 표 준업무지침에 따르면 세균 배양 검사에서 양성인 단위는 이식 에 사용될 수 없으며, 제대혈은행에서는 오염된 단위를 이식용 단위와 격리하게 된다.

국외 연구에 따르면 제대혈 오염률은 기관에 따라 $1-28 \%$ 까 지 다양하게 보고되고 있으며, 같은 기관 내에서도 시기에 따 라 다르게 나타남을 알 수 있다[5-7]. 오염률에 영향을 미치는 요소로는 분만방법, 채취인력, 배양방법 등이 있으며[5], 오염 되는 균의 종류는 주로 비뇨생식기, 장내 정상균무리였다[5-7]. 그러나 국내에서는 대규모의 제대혈을 바탕으로 한 관련 자료 가 발표된 바 없다. 
또 다른 의문은 영하 $190^{\circ} \mathrm{C}$ 의 냉동 저장이 오염된 단위 내의 세균에 미치는 영향이다. 적혈구나 혈소판 제제의 경우는 낮은 농도의 세균도 저장 과정에서 증식하여 임상적인 의미를 가지 는 농도에 이를 수 있는 것으로 알려져 있다[8,9]. 그러나 제대 혈의 경우, 유핵세포층을 농축하고, 동결보존제를 첨가하여 초 저온환경에 보관되며, 해동 후 즉시 이식에 사용되는 상황이므 로, 이런 조건에서 오염된 균이 어떤 영향을 받는지 잘 알려진 바가 없다.

이에 본 연구에서는 국내 최대규모의 기증제대혈은행에서 미생물 오염률을 알아보고, 오염균의 종류, 이와 관련된 인자를 밝히고자 하였다. 또한 격리하여 냉동 저장했던 세균 오염 단 위를 실제 이식과 동일한 조건으로 해동하여 저장 전과 해동 후의 배양 결과 차이를 살펴보았다.

\section{대상 및 방법}

2006년 5월부터 2012년 5월까지 제대혈기증에 자발적으로 동의 및 서명한 산모로부터 채취된 후, 제대혈은행에 접수되어 유핵세포농축처리 및 미생물배양검사가 시행된 21,236단위를 대상으로 후향적 분석을 하였다. 제대혈의 채취는 출산 시 분 만을 담당한 산부인과 의사가 태아 만출 직후 태반이 나오기 전에(in utero) 제대를 결찰하고 항응고제(citrate phosphate dextrose adenine, CPDA-1) $24.5 \mathrm{~mL}$ 가 포함된 채취백으로 절차에 따라 시행하였다. 제대혈은 운송 담당자가 실온에서 36 시간 이 내에 제대혈은행으로 운반하였다. 각 제대혈에 대해서 산모연 령, 신생아의 제태연령, 출생체중, 분만방법, 채취기관, 제대혈 무게에 대한 정보를 얻었다.

제대혈은 자동혈구분석기 XE-2100 (Sysmex, Kobe, Japan)을 이용하여 백혈구와 그 감별계수, 유핵적혈구, 혈소판, 혈색소 수치를 측정하였다. 배양 검사는 제대혈을 농축하는 과정의 부 산물인 혈장을 1쌍의 호기성 및 혐기성 BacT/ALERT 혈액배양 병(bioMérieux, Mercy-l'Etoile, France)에 각각 $10 \mathrm{~mL}$ 씩 접종하 였다. 접종한 배양병은 BacT/ALERT 자동혈액배양기(bioMérieux, Durham, NC, USA)에서 5일간 배양하여, 균이 검출되지 않으면 배양 음성으로 판독하였다. 균이 증식한 혈액배양액은 계대배양 후에 집락을 형성한 균을 Vitek 2 system (bioMérieux, Hazelwood, MO, USA)을 이용하여 동정하였다.

냉동 저장되었던 세균 오염 제대혈제제의 해동 후 검사를 위 하여 2006년부터 2009년까지 저장된 단위 중 각 연도에서 무 작위로 10 개씩을 선택하여 총 40 단위의 이식불가제대혈제제를 실험대상으로 결정하였다. 제대혈제제는 이식제대혈과 동일한 방법으로 해동 후, $2.5 \mathrm{~mL}$ 씩을 1쌍의 호기성 및 혐기성 혈액배 양병에 접종하고 저장 전 배양 검사와 동일하게 시행하였다. 배양된 균주에 대해서 동정 검사를 실시하였다.

통계 분석은 세균 오염군과 정상군으로 나누어 연속 변수는
중간값을 구하여 Mann-Whitney U test로, 비연속변수는 전체 수를 구하여 Pearson chi-square test로 그 차이의 유의성을 검증 하였다. 오염과 관련된 여러 변수에 대한 다변량분석은 모든 변수를 포함하여 후진 변수 제거법(backward elimination meth$\mathrm{od})$ 을 이용하여 다변량 로지스틱 회귀분석법을 이용하였다. 분 석 프로그램은 SPSS 16.0 (SPSS Inc., Chicago, IL, USA)을 이 용하였으며, $P$ value 0.05 이하를 유의한 결과로 보았다.

\section{결 과}

총 21,236단위 중에서 677단위에서 미생물 배양 양성으로 총 오염률은 $3.19 \%$ 였다. 각 연도별 오염률(평균과 표준편차)은 $3.2 \pm 0.4 \%$ 였고, 연도에 따른 유의한 차이는 없었다. 17 단위는 2 개 균주가 중복 오염되어서 오염 균주의 총 개수는 694개였으며, 37 종이 동정되었다. 정확히 동정되지 않은 그람양성 간균이 148 개(21.3\%)로 가장 많았고, Lactobacillus spp. 119개(17.1\%), Bacteroides spp. 70개(10.1\%), coagulase negative staphylococcus (CNS) 44개(6.3\%), Escherichia coli 29개(4.2\%)순으로 많았다 (Table 1). 동정이 안되는 경우가 28개(4.0\%), 동정 결과가 누락 된 경우가 17 개(2.4\%) 있었다. 동정된 각 균은 일반적인 상재 부위를 따라 비뇨생식기 및 소화기군이 387 개(55.8\%), 피부군 이 76 개( $11.0 \%)$, 환경군이 38 개(5.5\%)였다[5,10]. 이 분포의 연

Table 1. Micro-organisms isolated from culture positive umbilical cord blood units

\begin{tabular}{lc}
\hline Potential contamination source & Frequency (\%) \\
\hline Skin flora & 11.0 \\
Coagulase negative staphylococcus & 6.3 \\
Corynebacterium spp. & 3.1 \\
Staphylococcus aureus & 0.7 \\
Propionibacterium acnes & 0.4 \\
Micrococcus spp. & 0.4 \\
Gastrointestinal/urogenital flora* & 55.8 \\
Lactobacillus spp. & 17.1 \\
Bacteroides spp. & 10.1 \\
Escherichia coli & 4.2 \\
Enterococcus spp. & 4.1 \\
Streptococcus viridans group & 3.9 \\
Peptostreptococcus spp. & 3.4 \\
Prevotella spp. & 3.4 \\
Lactococcus spp. & 2.1 \\
Klebsiella spp. & 1.9 \\
Clostridium spp. & 1.2 \\
Environmental contaminants* & 5.5 \\
Citrobacter spp. & 1.2 \\
Pseudomonas spp. & 1.0 \\
Unidentified Gram positive bacilli & 21.3 \\
Missing data & 2.4 \\
\hline
\end{tabular}

*Species with frequency over $1.0 \%$ were presented. 
도별 변화를 보면 최근에 피부군과 환경군이 유의하게 줄어들 었다 $(P<0.001)$ (Fig. 1). 오염 단위를 분만 방법에 따라서 분류 하면 정보가 없는 6개를 제외하고 질식분만이 634개(93.6\%), 제왕절개가 37 개(5.5\%)였다. 300 단위 이상 접수한 채취 기관 중에서 한 곳이 다른 기관들의 평균보다 유의하게 높은 오염률 을 보였다( $25.4 \%$ vs. $2.9 \%, P<0.001)$ (Table 2). 해당 기관에서 질식분만의 비율이 더 높은 것은 아니었으며, 오염균을 분석하 면 피부군의 비율이 다른 기관들에 비해 유의하게 높았다 (29.4\% Vs. $11.2 \%, P<0.001)$. 제대혈 오염과 연관된 산모 및 태아의 관련 인자와 제대혈 관련 변수들을 밝히기 위한 단변량 분석을 하였다. 오염률은 질식분만과 앞서 언급한 한 기관에서 채취한 단위가 유의하게 높았으며, 오염된 단위는 정상 단위에

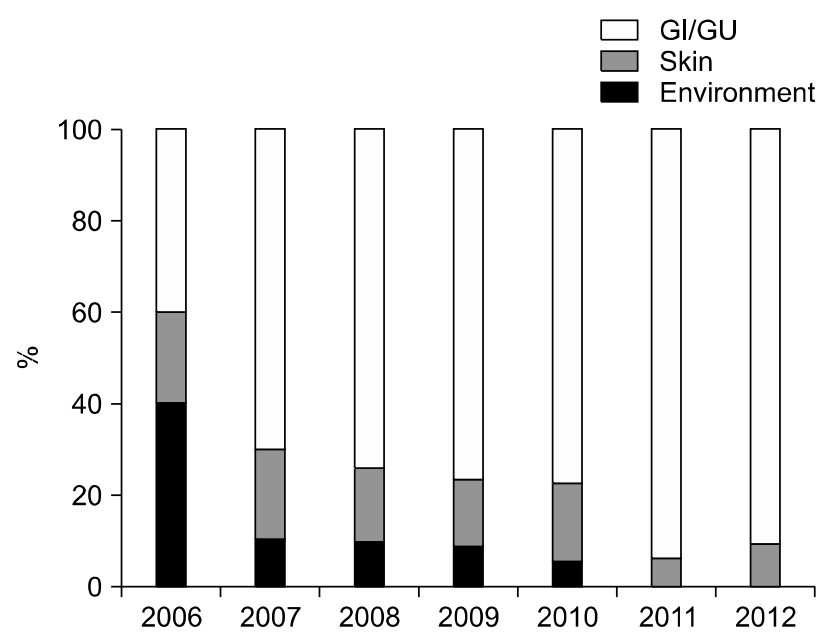

Fig. 1. Proportions of origin of contaminated microorganisms according to years. Abbreviations: GI, gastrointestinal; GU, genitourinary.
비해 유의하게 채취된 부피가 작았고, 처리시간이 짧았으며, 백 혈구와 유핵적혈구의 수가 많았다(Table 3). 다변량 분석을 하 였을 때, 질식분만이 제왕절개에 비해 약 7배, 한 기관이 다른 기관에 비해 약 13 배로 제대혈이 오염될 가능성이 높았다 (Table 4). 제대혈의 부피, 처리시간, 혈색소, 유핵적혈구수는 오염과 유의한 관계는 있었지만 정도는 미미했다. 해동한 40단 위의 오염 검체로 다시 실시한 배양 검사에서는 18 개(45\%)가 배양 음성이었다. 6 개( $15 \%)$ 는 동정되는 균의 종류나 수에 변화

Table 2. Contamination rate of umbilical cord blood unit according to collection center

\begin{tabular}{crrrr}
$\begin{array}{c}\text { Collection } \\
\text { center }\end{array}$ & $\begin{array}{c}\text { Culture positive } \\
\text { units (N) }\end{array}$ & $\begin{array}{c}\text { Stored } \\
\text { units (N) }\end{array}$ & $\begin{array}{c}\text { Contamina- } \\
\text { tion rate }(\%)\end{array}$ & $\begin{array}{c}\text { Vaginal delivery } \\
\text { rate }(\%)\end{array}$ \\
\hline A & 28 & 1,795 & 1.6 & 77.5 \\
B & 65 & 1,721 & 3.8 & 61.4 \\
C & 11 & 1,063 & 1.0 & 59.4 \\
D & 20 & 786 & 2.5 & 77.6 \\
E & 17 & 766 & 2.2 & 75.2 \\
F & 12 & 669 & 1.8 & 78.3 \\
G & 31 & 599 & 5.2 & 67.8 \\
H & 127 & 501 & $25.3 *$ & 73.7 \\
I & 15 & 485 & 3.1 & 84.5 \\
J & 29 & 483 & 6.0 & 51.1 \\
K & 26 & 473 & 5.5 & 82.9 \\
L & 7 & 414 & 1.7 & 70.0 \\
M & 10 & 385 & 2.6 & 75.8 \\
N & 9 & 364 & 2.5 & 79.1 \\
O & 6 & 360 & 1.7 & 66.7 \\
P & 15 & 347 & 4.3 & 74.1 \\
Q & 20 & 320 & 6.3 & 70.3 \\
R & 2 & 309 & 0.6 & 74.8 \\
\hline
\end{tabular}

*H center vs. other centers, $P<0.001$

Table 3. Univariate analysis for parameters associated with the contamination of cord blood units

\begin{tabular}{|c|c|c|c|}
\hline & Culture positive & Culture negative & $P$ \\
\hline \multicolumn{4}{|l|}{ Type of delivery, N (\%) } \\
\hline Vaginal delivery & $634(4.1)$ & $14,987(95.9)$ & $<0.001$ \\
\hline Cesarean section & $37(0.7)$ & $5,420(99.3)$ & \\
\hline \multicolumn{4}{|l|}{ Collection center, N (\%) } \\
\hline $\mathrm{H}$ center* & $127(25.3)$ & 374 (74.7) & $<0.001$ \\
\hline Other centers & $550(2.7)$ & $20,176(97.3)$ & \\
\hline Maternal age (years) ${ }^{\dagger}$ & $31(29-34)$ & $31(29-33)$ & 0.728 \\
\hline Gestational age (months) $^{\dagger}$ & $39(39-40)$ & $39(38-40)$ & 0.067 \\
\hline Birth weight $(\mathrm{kg})^{\dagger}$ & $3.35(3.12-3.60)$ & $3.34(3.10-3.60)$ & 0.852 \\
\hline Volume of cord blood $(\mathrm{mL})^{\dagger}$ & $105.8(95.2-118.9)$ & $108.0(96.6-122.0)$ & $<0.001$ \\
\hline Processing time (hours) ${ }^{\dagger}$ & $25(22-29)$ & $26(23-30)$ & 0.003 \\
\hline White blood cell $\left(\times 10^{3} / \mathrm{uL}\right)^{\dagger}$ & $10.7(9.3-12.9)$ & $10.6(8.9-12.6)$ & 0.006 \\
\hline Platelet $\left(\times 10^{3} / \mathrm{uL}\right)^{\dagger}$ & $210(186-238)$ & $208(183-234)$ & 0.089 \\
\hline Hemoglobin $(g / d L)^{\dagger}$ & $11.6(10.8-12.4)$ & $11.7(10.9-12.6)$ & 0.125 \\
\hline Nucleated RBC $(/ 100 \mathrm{WBC})^{\dagger}$ & $2.2(1.2-4.7)$ & $2.0(1.0-3.9)$ & $<0.001$ \\
\hline
\end{tabular}

*See Table $2 ;{ }^{\dagger}$ The values are presented as the median and interquartile range. 
Table 4. Multivariate logistic regression for parameters associated with the contamination of cord blood units

\begin{tabular}{lccc}
\hline & Beta coefficient & Odds ratio & $95 \%$ Confidence interval \\
\hline Vaginal delivery* $^{\dagger}$ & 1.938 & 6.942 & $4.891-9.854$ \\
H center $^{*}$ & 2.548 & 12.777 & $10.160-16.068$ \\
Volume of cord blood (mL) & -0.007 & 0.993 & $0.988-0.998$ \\
Processing time (hours) & -0.011 & 0.989 & $0.979-1.000$ \\
Hemoglobin (g/dL) & -0.06 & 0.942 & 0.001 \\
Nucleated RBC (/100 WBC) & 0.02 & 1.02 & $0.0482-1.005$ \\
\hline
\end{tabular}

*Cesarean section was set as the reference group; ${ }^{\dagger}$ See Table 2 ; Other centers were set as the reference group.

Table 5. Discordant culture results of contaminated cord blood units between pre-freeze and post-thaw

\begin{tabular}{|c|c|c|}
\hline ID No. & Pre-freeze & Post-thaw \\
\hline $06-1$ & ID-unknown & No growth \\
\hline $06-2$ & ID-unknown & No growth \\
\hline \multirow[t]{3}{*}{$06-4$} & Citrobacter freundii & Klebsiella pneumoniae \\
\hline & Klebsiella pneumoniae & Citrobacter freundii \\
\hline & & Enterococcus casseliflavus \\
\hline $06-6$ & Unknown gram positive rod & No growth \\
\hline $06-8$ & Streptococcus viridans group & No growth \\
\hline $06-9$ & Unknown gram positive rod & No growth \\
\hline $06-10$ & Coagulase negative staphylococcus & No growth \\
\hline $07-1$ & Bifidobacterium spp. & No growth \\
\hline $07-4$ & Bacteroides ovatus & Pediococcus pentosaceus \\
\hline $07-5$ & Bacteroides merdae & No growth \\
\hline \multirow[t]{2}{*}{$07-7$} & Neisseria flavescens & No growth \\
\hline & Streptococcus viridans group & \\
\hline $07-8$ & Coagulase negative staphylococcus & No growth \\
\hline $08-1$ & Escherichia coli & Klebsiella pneumoniae \\
\hline $08-2$ & Bacteroides vulgatus & Lactobacillus spp. \\
\hline $08-4$ & Corynebacterium spp. & No growth \\
\hline $08-5$ & Lactobacillus spp. & No growth \\
\hline $08-6$ & Coagulase negative staphylococcus & No growth \\
\hline $08-7$ & Peptostreptococcus anaerobius & Lactobacillus spp. \\
\hline $08-9$ & Bacteroides uniformis & No growth \\
\hline $08-10$ & Prevotella bivia & No growth \\
\hline $09-2$ & Corynebacterium spp. & No growth \\
\hline $09-6$ & Lactobacillus spp. & No growth \\
\hline $09-9$ & Lactobacillus spp. & Escherichia coli \\
\hline $09-10$ & Corynebacterium spp. & No growth \\
\hline
\end{tabular}

Abbreviation: ID, identification.

를 보였다(Table 5). 저장 기간은 배양 결과의 변화와 유의한 관계가 없었다.

\section{고 찰}

외국의 보고들을 고려할 때, 본 연구의 제대혈 오염률 $3.19 \%$ 는 높지 않은 편에 속한다. 본 연구에서는 개설 기간에 따른 오 염률의 유의한 변동은 관찰되지 않았다.

동정이 된 오염균 중에서 대부분 $(80 \%)$ 이 비뇨생식기 및 장 내 정상균무리에 속했다. 오염 단위의 $94 \%$ 가까이가 질식분만
에서 채취한 것임을 감안할 때, 제대나 의료진의 손에 오염되 어 있던 비뇨생식기 및 소화기에서 유래한 일과성 미생물이 채 취 과정에서 오염되었을 가능성이 높아 보인다. 외국의 보고에 의하면 피부 정상균무리가 가장 많이 분리되었으며[5], 특히 Propionibacterium spp.가 $13.7 \%$ 를 차지했는데 이는 본 연구에 서 $0.4 \%$ 밖에 분리되지 않은 것과 차이를 보였다. 이는 BacT/ ALERT를 이용한 혈액오염연구에서 Propionibacterium spp.의 검출감도가 낮은 것과 연관이 될 것으로 생각되나[11] 해당 연 구도 동일한 혈액배양시스템을 사용한 바, 오염정도의 차이로 생각한다.

제대혈을 이용한 미생물 오염연구들에 의하면, 제대혈의 세 균 오염은 질식분만, 산부인과 의료진의 채취, 성인용 혐기성 배양병과 소아용 배양병의 사용에서 높으며, 혐기성균은 호기 성 배양병에서 검출률이 매우 낮으므로 혐기성 배양병을 병용 할 것을 권장하고 있다[5]. 배양 검사의 검체 양을 늘리면 양성 률이 올라가며, 검체의 종류는 침전 적혈구, 혈장, 농축 제대혈 중 어느 것을 사용해도 양성률이 다르지 않았다[7]. 본 연구에 서는 성인용 호기성 및 혐기성 배양병을 사용하여 검출한 결과 로, 질식분만이 오염과 유의하게 연관된 것은 동일했으나, 특이 한 점은 한 채취 기관이 오염률과 가장 큰 연관성을 가진 것이 었다. 해당 기관의 오염률은 다른 기관의 5-20배에 이르렀다. 오염균 중 피부 정상균무리의 비율이 유의하게 높은 것으로 볼 때, 채취자의 손이 주요 오염원으로 작용했을 가능성이 있다. 외국의 경우 초기에는 $28 \%$ 에 육박하던 오염률이 채취 방법과 지침을 개선함으로써 $4 \%$ 대까지 낮아졌음을 보고한 바 있다[12]. 이에 질 향상 계획의 일부로써, 해당 기관을 포함한 모든 채취 산과병원에 채취 방법의 개선을 권유했으며, 향후에 오염률 변 화를 관찰할 예정이다.

냉동 저장되어 있던 오염 제대혈제제를 해동하여 배양 검사한 결과 $60 \%$ 에서 $(45 \%$ 배양 음성, $15 \%$ 다른 균) 저장 전 제대혈과 상이한 배양결과를 보였다. 제대혈제제에서의 배양음성 원인 으로는 검체량을 가장 큰 원인으로 생각할 수 있다[7,13]. 이는 균 수가 적을 경우 채취분획에 따라 배양결과에 영향을 줄 것 이기 때문에 향후 오염 제대혈의 미생물 오염정도에 대하여 연 구해 볼 여지가 있다. 두 번째로 냉동보존제인 Dimethylsulfox- 
ide (DMSO)의 영향을 생각해볼 수 있는데, 이는 세포 내로 침 투하여 세포 내 수분을 감소시켜서 동결 시 결정 형성을 억제 하는 역할을 하는데, 일반적으로 미생물의 동결 장기 보존에도 사용되지만, 살균 및 정균 작용도 보고된 바 있다[14]. 세 번 째로 냉동자체에 의한 영향도 있으며, 적혈구에 오염되었던 Staphylococcus epidermidis, Pseudomonas aeruginosa의 숫자가 냉동 저장 후 감소함을 보고한 연구가 있다[15]. 그들은 혈액제 제 내에 있던 백혈구가 냉동-해동 과정에서 분해되면서 나오는 살균 물질이 원인일 것이라 추측했다. 또 다른 일부 제대혈제 제에서는 제대혈에서 동정되지 않던 균이 해동 후에 동정된 경 우도 있었으며, 균 명이 바뀐 경우가 있었다. 이는 저장 전 배 양 검사에서 혼합균의 경우에 검체가 제대혈로 정확한 동정을 필요로 하지 않으므로, 검사자가 간과했을 가능성도 배제할 수 없다.

본 연구의 제한점은 해동제대혈제제의 수가 적고, 이 중 동 정을 하지 않고 단지 미생물 배양으로 보고된 제대혈을 포함하 여 분석의 여지가 적었던 것이다. 이에 대하여는 대규모의 냉 동-해동연구를 진행 중이며, 새로운 결과가 조만간 추가될 예 정이다. 또 하나의 제한점은 일반적인 혈액배양법으로 배양되지 않는 비뇨생식기의 주요한 오염균인 Mycoplasma와 Ureaplasma 의 존재 여부를 검사하지 않은 것이다. 그러나 본 기관에서 이 전에 시행한 연구에서 상기 미생물의 DNA 검출을 시도하였으 나 양성인 단위는 없었다[16,17].

결론적으로 본 연구는 국내 최초로 대규모로 제대혈에서 세 균의 오염률과 오염균의 분포를 살펴 보았으며, 이를 바탕으로 혈액제제의 경우와 같이 제대혈의 오염률 또한 채취기관의 질 관리지표로 활용가능할 것이다. 또한 소중한 자원인 제대혈의 불필요한 폐기를 줄이기 위해 채취에 대한 적절한 지침을 개발 하고 교육할 필요가 있다. 또한 제대혈제제 해동 후의 미생물 배양결과가 제대혈과 차이를 보이므로, 제대혈의 오염 미생물 정도와 종류에 따라 제대혈을 재분류함으로써, 기왕 저장처리 된 제대혈의 활용가능성에 대한 향후 연구의 여지를 열어놓게 되었다.

\section{참 고 문 헌}

1. U.S. Department of Health and Human Services, Food and Drug Administration, Center for Biologics Evaluation and Research. ed. Guidance for Industry: Minimally Manipulated, Unrelated Allogeneic
Placental/Umbilical Cord Blood Intended for Hematopoietic Reconstitution for Specified Indications. Rockville; Office of Communication, Outreach and Development (OCOD), 2009.

2. American Association of Blood Banks. ed. Standards for Cellular Therapy Product Services. 5th ed, Bethesda Md.; AABB, 2011.

3. Foundation for the Accreditation of Cellular Therapy (FACT). NetCord-FACT International Standards for Cord Blood Collection, Banking, and Release for Administration. 4th ed. http://www. factweb.org/ [Online] (last visited on 7 August 2012).

4. Umbilical Cord Blood Management and Research Act. Korea Ministry of Health and Welfare, 2011. http://law.go.kr/ [Online] (last visited on 7 August 2012).

5. Clark P, Trickett A, Stark D, Vowels M. Factors affecting microbial contamination rate of cord blood collected for transplantation. Transfusion 2012;52:1770-7.

6. Kamble R, Pant S, Selby GB, Kharfan-Dabaja MA, Sethi S, Kratochvil K, et al. Microbial contamination of hematopoietic progenitor cell grafts-incidence, clinical outcome, and cost-effectiveness: an analysis of 735 grafts. Transfusion 2005;45:874-8.

7. Honohan A, Olthuis H, Bernards AT, van Beckhoven JM, Brand A. Microbial contamination of cord blood stem cells. Vox Sang 2002;82:32-8.

8. Morrow JF, Braine HG, Kickler TS, Ness PM, Dick JD, Fuller AK. Septic reactions to platelet transfusions. A persistent problem. JAMA 1991;266:555-8.

9. Tipple MA, Bland LA, Murphy JJ, Arduino MJ, Panlilio AL, Farmer JJ 3rd, et al. Sepsis associated with transfusion of red cells contaminated with Yersinia enterocolitica. Transfusion 1990;30: 207-13.

10. Versalovic J, American Society for Microbiology. eds. Manual of Clinical Microbiology. 10th ed, Washington, DC; ASM Press, 2011.

11. McDonald CP, Rogers A, Cox M, Smith R, Roy A, Robbins S, et al. Evaluation of the 3D BacT/ALERT automated culture system for the detection of microbial contamination of platelet concentrates. Transfus Med 2002;12:303-9.

12. Armitage S, Warwick R, Fehily D, Navarrete C, Contreras M. Cord blood banking in London: the first 1000 collections. Bone Marrow Transplant 1999;24:139-45.

13. Mermel LA and Maki DG. Detection of bacteremia in adults: consequences of culturing an inadequate volume of blood. Ann Intern Med 1993;119:270-2.

14. Basch $\mathrm{H}$ and Gadebusch $\mathrm{HH}$. In vitro antimicrobial activity of dimethylsulfoxide. Appl Microbiol 1968;16:1953-4.

15. Kahn RA, Meryman HT, Syring RL, Flinton LJ. The fate of bacteria in frozen red cells. Transfusion 1976;16:215-20.

16. Roh EY, Yoon JH, Chang JY, Hwang KR, Song EY, Shin S. Analysis of mycoplasma contamination in donated cord blood units. Korean J Blood Transfus 2008;19:9-14.

17. Roh EY, Shin S, Yoon JH, Chang JY. Ureaplasma contamination rate in donated cord blood units. Korean J Blood Transfus 2008; 19:239-44. 
$=$ 국문초록=

\title{
기증제대혈의 미생물 오염
}

\author{
${ }^{1}$ 서울대학교 의과대학 검사의학교실, ${ }^{2}$ 서울대학교 보라매병원 진단검사의학과, \\ ${ }^{3}$ 서울대학교 보라매병원 소아과, ${ }^{4}$ 서울특별시 제대혈은행 \\ 박정수 ${ }^{1,2,4}$, 신 수 $^{1,2,4}$, 윤종현 ${ }^{1,2,4}$, 노은연 ${ }^{1,2,4}$, 장주영 ${ }^{3}$, 김의종 $^{1}$
}

배경: 제대혈에서 유래한 동종세포치료제제의 안전성을 검증하기 위해서는 미생물 오염에 대한 검사가 필수적이다. 이 에 본 연구에서는 국내 최대의 기증제대혈은행에서 제대혈의 오염 정도와 이에 영향을 미치는 인자를 분석하였다. 또한 냉동 저장이 제대혈에 오염된 균에 미치는 영향을 알아보았다.

방법: 제대혈은 제대혈은행의 표준업무지침에 따라 채취, 운반, 처리 및 저장되었다. 미생물 배양 및 동정 검사는 저장 전 제대혈 혈장 5-10 mL를 BacT/ALERT 혈액배양병(bioMérieux, France)에 분주하여 통상적인 방법으로 시행하였다. 냉동 저장되어 있던 오염 제대혈 중 무작위로 40 개를 선택해서 해동하고 $2.5 \mathrm{~mL}$ 를 취하여 상기와 같이 배양 검사를 시행하였다. 결과: 전체 21,236 단위 중에서 677 단위(3.19\%)가 배양 양성이었다. Lactobacillus spp. (17.2\%)가 가장 많이 배양되었고, Bacteroides spp. (10.1\%), coagulase negative staphylococcus (6.4\%)순으로 많이 배양되었으며, 이외 그람양성 간균이 $21.4 \%$ 에서 배양되었다. 오염률은 제왕절개에서보다 질식분만에서 높았으며 $(4.1 \%$ vs. $0.7 \%, P<0.001)$, 채취 기관별로도 차이 가 있었다 $(0.7-25.4 \%, P<0.001)$. 오염 제대혈의 해동 후 배양에서는 $55 \%$ 에서만 미생물이 배양되었다.

결론: 본 연구는 국내에서 대규모로 제대혈의 오염률을 살펴보았다. 이는 제대혈 채취기관의 질 관리를 위한 기초자료로 활용이 가능할 것이다. 냉동 저장 후에 오염 제대혈의 미생물 배양률이 낮아진 것은 추가 연구를 통해 오염 미생물 양의 감소를 검증할 필요가 있을 것이다. [Ann Clin Microbiol 2013;16:39-44]

교신저자 : 윤종현, 신 수, 156-707, 서울시 동작구 보라매로5길 20

서울대학교 보라매병원 진단검사의학과

Tel: 02-870-2601, Fax: 02-870-2620

E-mail: slice@paran.com 